\title{
New Therapeutic Landscape in Neuromyelitis Optica
}

Madina Tugizova, $M D^{1,2}$

Luka Vlahovic, MD, MSCR

Anna Tomczak, MS ${ }^{1,2}$

Nora Sandrine Wetzel ${ }^{1,4}$

May Htwe Han, $M D^{1,2, *}$

\author{
Address \\ ${ }^{1}$ Department of Neurology, Division of Neuroimmunology, Stanford University, \\ 1201 Welch Road, MSLS p212, Stanford, CA, 94305, USA \\ ${ }^{*}, 2$ Multiple Sclerosis Center, Stanford Hospital and Clinics, Palo Alto, CA, USA \\ Email: mayhan@stanford.edu \\ ${ }^{3}$ Department of Neurology, Creighton University School of Medicine, Omaha, NE, \\ USA \\ ${ }^{4}$ Faculty of Medicine, University of Zurich, Zürich, Switzerland
}

Published online: 30 March 2021

(C) The Author(s), under exclusive licence to Springer Science+Business Media, LLC part of Springer Nature 2021

Madina Tugizova and Luka Vlahovic contributed equally to this work.

This article is part of the Topical Collection on Multiple Sclerosis and Related Disorders

Keywords Neuromyelitis optica spectrum disorder (NMOSD) $\cdot$ B cells $\cdot$ CD20 $\cdot$ Complement $\cdot$ AQP4 $\cdot$ MOG

\section{Abstract}

Purpose of review This review discusses the current treatment trends and emerging therapeutic landscape for patients with neuromyelitis optica spectrum disorder (NMOSD). Recent findings Conventional immune suppressive therapies, such as B cell depletion, have been used for long-term treatment. However, the availability of recent FDA-approved and investigational drugs has made therapeutic choices for NMOSD more complex. Summary Recent randomized clinical trials have shown that eculizumab, inebilizumab, and satralizumab are efficacious therapies for AQP4 seropositive NMOSD. These therapies may not have the same benefit in patients with seronegative NMOSD, including MOGassociated disease, and further investigation is required in this population. Reliable biomarkers to guide therapy decisions are urgently needed. There is a plethora of promising investigational therapies currently in the pipeline with exciting and novel mechanisms of action. 


\section{Introduction}

Neuromyelitis optica spectrum disorder (NMOSD) is a central nervous system (CNS) autoimmune inflammatory demyelinating disorder, which primarily causes optic neuritis and transverse myelitis, however can also present with cerebral syndromes [1-3]. Approximately three-quarters of patients with NMOSD have antibodies against aquaporin-4 (AQP4), a water-channel protein abundantly expressed in astrocyte foot processes [4, 5]. However, the spectrum of NMOSD has expanded with the identification of novel autoantibodies, including those against myelin oligodendrocyte glycoprotein (MOG) [6].

B cells play a central role in the pathogenesis of NMOSD [7]. They are generated in the bone marrow from hematopoietic stem cells and proceed through stages of maturation by expressing unique surface markers, including CD19, a pan B cell marker expressed throughout the life span of a $\mathrm{B}$ cell, and CD20, which is expressed starting at the pre- $\mathrm{B}$ cell stage, before being downregulated at the stage of plasma cells and plasmablasts (Fig. 1) [8]. Immune activation is initiated in the peripheral immune system where pathogenic AQP4 antibodies are generated by plasmablasts in an interleukin-6dependent manner [7-9]. AQP4 autoantibodies enter the CNS and bind to AQP4 in foot processes of blood-brain barrier (BBB) astrocytes (Fig. 1) [7, 9]. The antibody-antigen complexes activate the proteolytic classical complement cascade, resulting in generation of complement $\mathrm{C} 5$, a component of the membrane attack complex that causes astrocyte death and demyelination (Fig. 1) [10, 11].

T cells also contribute to the immunopathogenesis of NMOSD; however, their functions are less well defined [12]. Animal models provide evidence that AQP4specific $T$ cells cause inflammatory CNS lesions [13]. $\mathrm{NMO} \operatorname{IgG}$ is primarily of the IgG1 subclass [14], and T helper cells are crucial for immunoglobulin class switching to generate IgG1 subclass AQP4 antibodies [15]. In addition, patients with NMOSD have higher proportions of Th17 cells compared to healthy controls [16]. Studies suggest that high IL-6 expression in NMOSD patients may enhance the reciprocal activation of Th17 cells [17] and upregulation of Th2-related cytokines $[18,19]$.

\section{Conventional therapies}

In contrast to multiple sclerosis (MS), functional decline and permanent disability in NMOSD are primarily impacted by severe, often life-threatening clinical relapses $[20,21]$. Therefore, the treatment strategy for patients diagnosed with NMOSD [22-24] consists of aggressive management of acute relapses followed by long-term preventative immunosuppressive therapies, as outlined in Fig. 2.

The goals of acute treatment are to curtail active inflammation, hasten recovery, and limit irreversible damage. The mainstay of treatment is high-dose IV methylprednisolone $1000 \mathrm{mg}$ for 3-5 days [25]. An oral steroid taper following IV steroids is recommended in severe cases; however, there is limited data on this practice [26]. Plasmapheresis (PLEX) 5-7 cycles on alternate days can be used in conjunction with steroids to simultaneously target cellular and humoral immune responses in refractory cases $[26,27]$. There is evidence of improved clinical benefit with early initiation of PLEX [28]. If used concomitantly with PLEX, steroids should be administered following a PLEX session, in which case less than $1 \%$ of the steroid dose is removed [28]. 


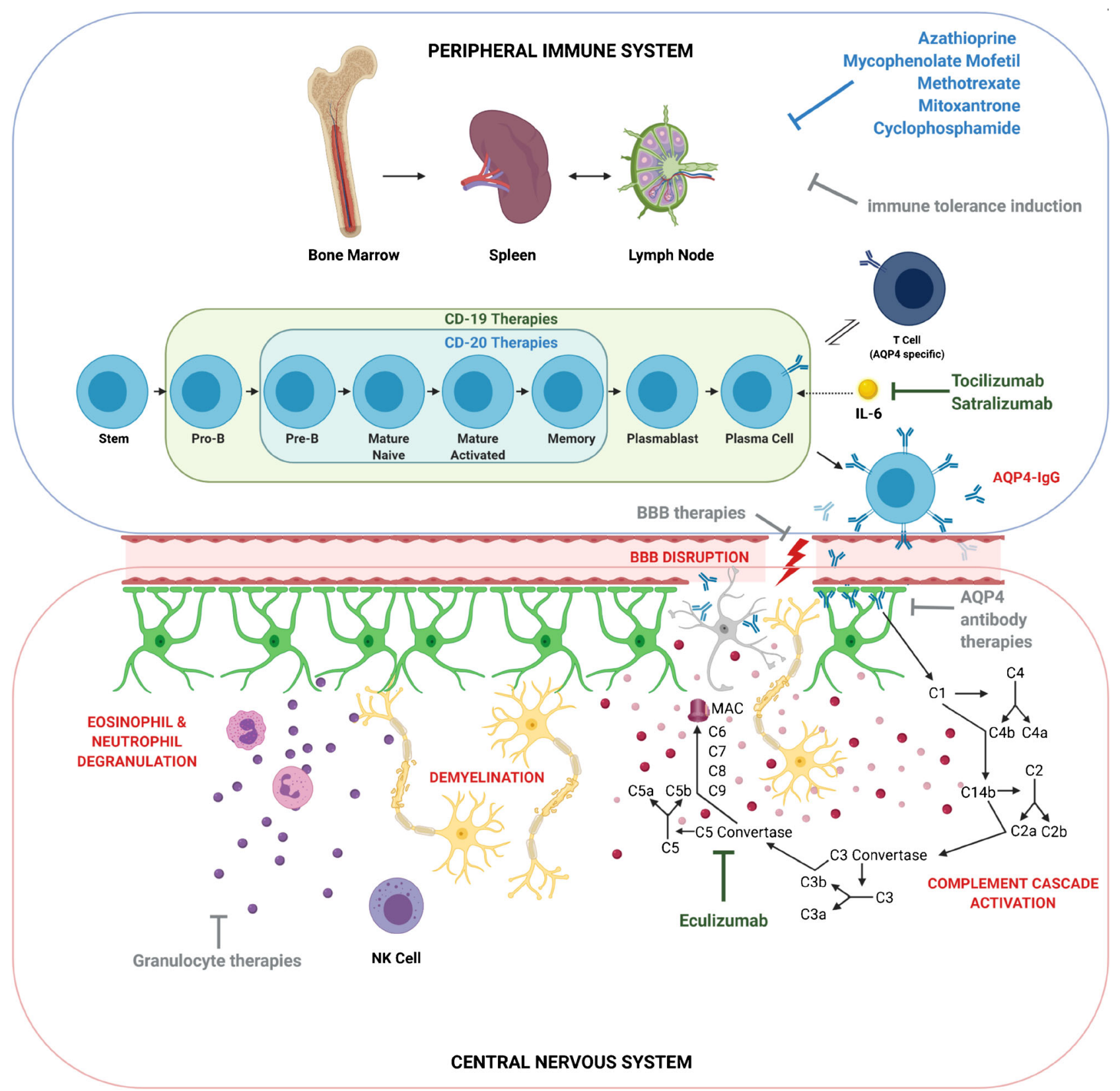

Fig. 1. NMOSD pathogenesis and therapeutic targets in the peripheral immune and central nervous systems. B cells undergo maturation in the bone marrow, spleen, and lymph nodes, ultimately to generate anti-AQP4-expressing plasmablasts. Pathogenic AQP4 antibody enters the CNS via the defective blood-brain barrier to target astrocytes with resultant neuroinflammation and demyelination. Conventional (blue), new maintenance (green), and emerging (gray) therapies are depicted in respective checkpoints involved in NMOSD pathogenesis. AQP4 aquaporin 4, BBB blood-brain barrier, C complement factor, CD cluster of differentiation, IgG immunoglobulin G, IL interleukin, MAC membrane attack complex, NK natural killer cell. Created with BioRender.com. 


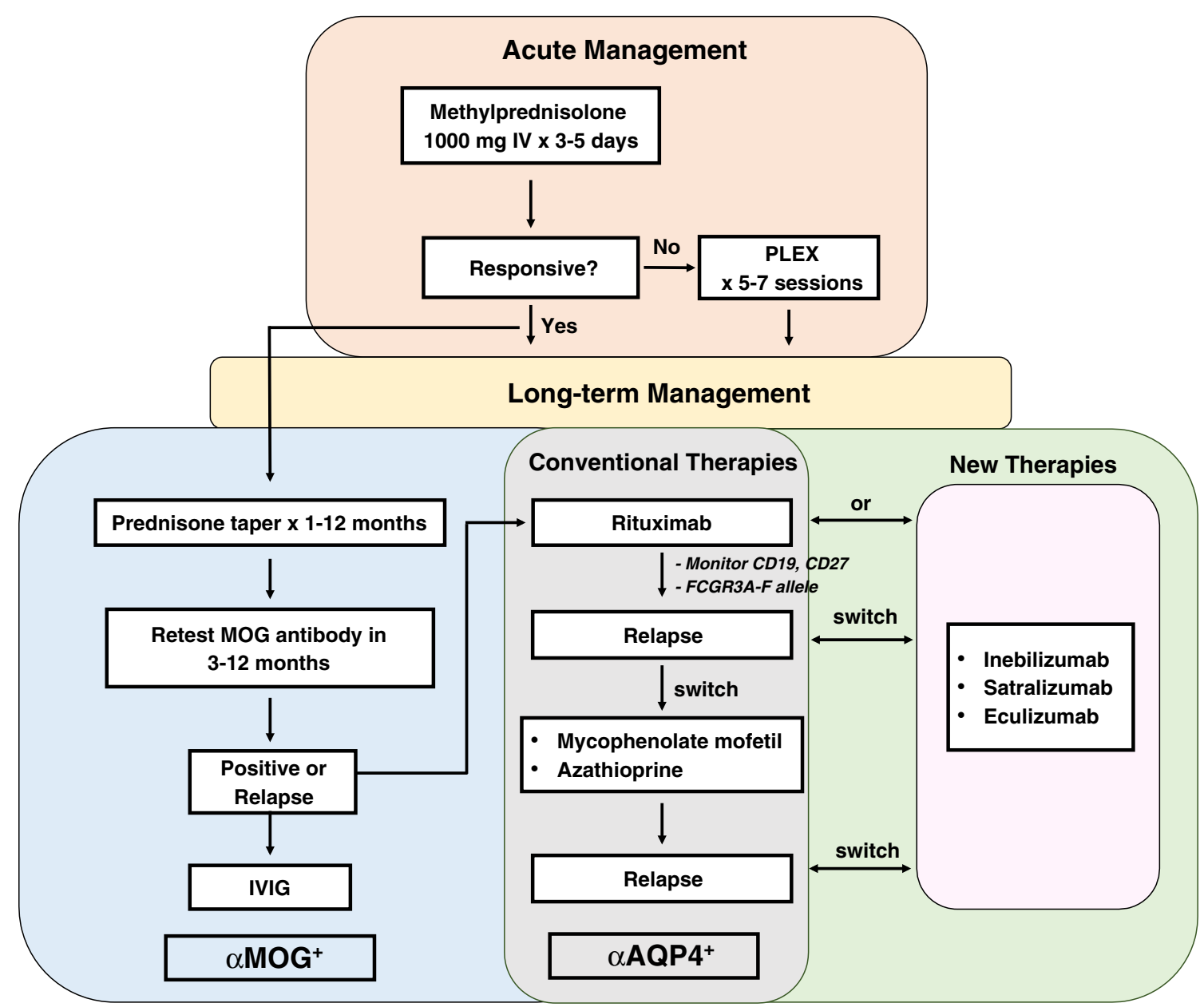

Fig. 2. Recommended treatment algorithm for acute and long-term management of aquaporin 4 antibody positive ( $\left(\mathrm{AQP} 4^{+}\right)$and myelin oligodendrocyte glycoprotein antibody positive $\left(\alpha \mathrm{MOG}^{+}\right)$NMOSD. Acute management does not differ by serostatus, but there are more specific long-term treatments for patients based on antibody status. Conventional therapies can be used for $\alpha \mathrm{AQP}^{+}$, $\mathrm{aMOG}^{+}$, or seronegative patients. New therapies have shown efficacy in $\alpha \mathrm{AQP}^{+}$patients. inebilizumab and satralizumab may be considered for use as first-line therapies. Eculizumab has proven effectiveness as an add-on therapy but may be reasonable to use as monotherapy. PLEX plasma exchange.

\section{Maintenance therapies}

There were no FDA-approved immune therapies for NMOSD prior to June 2019. The most commonly used conventional maintenance therapies are rituximab, azathioprine, and mycophenolate mofetil, which have been used off label for decades [25]. Immunosuppressive therapies such as methotrexate, mitoxantrone, and cyclophosphamide have been shown to be beneficial in highly active NMOSD, but are infrequently used due to their less favorable risk-benefit profiles [29-32].

\section{Rituximab (Rituxan ${ }^{\text {T }}$ )}

Rituximab is a chimeric monoclonal antibody that targets CD20 (Fig. 1; Table 1) [33]. A small open label study in 2005 showed that rituximab 
Table 1. Summary of NMOSD clinical trials. IV intravenous, SC subcutaneous, $C$ complement, $C D$ cluster of differentiation, $A Q P 4$ aquaporin $4, I L$ interleukin, $N / A$ not applicable

\begin{tabular}{|c|c|c|c|c|c|}
\hline & Prevent & N-MOmentum & TANGO & SAkuraSky & SAkuraStar \\
\hline Drug & Eculizumab & Inebilizumab & $\begin{array}{r}\text { Tocilizumab vs } \\
\text { azathioprine }\end{array}$ & Satralizumab & Satralizumab \\
\hline Mechanism & Anti-C5 & Anti-CD19 & $\begin{array}{l}\text { Tocilizumab: } \\
\text { anti-IL-6 } \\
\text { receptor; } \\
\text { azathioprine: } \\
\text { impairs DNA } \\
\text { replication }\end{array}$ & $\begin{array}{l}\text { Anti-IL-6 } \\
\text { receptor }\end{array}$ & $\begin{array}{l}\text { Anti-IL-6 } \\
\text { receptor }\end{array}$ \\
\hline Dose & $\begin{array}{l}900 \text { mg IV q1 } \\
\text { week } \times 4 \\
\text { doses, then } \\
1200 \text { mg IV } \\
\text { on week } 5 \\
\text { and q2 weeks } \\
\text { therafter }\end{array}$ & $\begin{array}{l}300 \text { mg IV two } \\
\text { weeks apart, } \\
\text { then q } 6 \\
\text { months }\end{array}$ & $\begin{array}{l}\text { Tocilizumab: } \\
8 \mathrm{mg} / \mathrm{kg} \text { IV } \\
\text { q4 weeks; } \\
\text { azathioprine: } \\
2-3 \mathrm{mg} / \mathrm{kg} / \text { day } \\
\text { P0 }\end{array}$ & $\begin{array}{l}120 \mathrm{mg} \mathrm{SC} \text { on } \\
\text { weeks } 0,2 \text {, } \\
\text { and } 4 \text {, then } \\
\text { q4 weeks }\end{array}$ & $\begin{array}{c}120 \text { mg SC on } \\
\text { weeks } 0,2 \text {, } \\
\text { and } 4 \text {, then } \\
\text { q4 weeks }\end{array}$ \\
\hline Number of patients & 143 with 2:1 & & $\begin{array}{l}\text { randomization } \\
(96+47)\end{array}$ & 230 with $3: 1$ & \\
\hline $\begin{array}{l}\text { randomization } \\
(174+56)\end{array}$ & 118 with $1: 1$ & & $\begin{array}{l}\text { randomization } \\
(59+59)\end{array}$ & 83 with $1: 1$ & \\
\hline $\begin{array}{l}\text { randomization }(41+ \\
42)\end{array}$ & 95 with 2:1 & & $\begin{array}{l}\text { randomization } \\
(63+32)\end{array}$ & & \\
\hline AQP4 antibody status & $100 \% \mathrm{AQP} 4+$ & $93 \%$ AQP4 + & $\begin{array}{l}\text { Tocilizumab: } 85 \% \\
\text { AQP4 +; } \\
\text { azathioprine: } \\
90 \% \text { AQP4 + }\end{array}$ & $70 \%$ AQP4 + & $70 \%$ AQP4 + \\
\hline $\begin{array}{l}\text { Concomitant } \\
\text { immunosuppression }\end{array}$ & Yes & No & Yes & Yes & No \\
\hline Age inclusion criteria & $\geq 18$ years & $\geq 18$ years & $\geq 18$ years & $12-74$ years & $18-74$ years \\
\hline EDSS inclusion criteria & $\leq 7$ & $\leq 8$ & $\leq 7.5$ & $\leq 6.5$ & $\leq 6.5$ \\
\hline Relapse rate & $\begin{array}{l}\text { Eculizumab: } \\
\text { 3/96 (3\%); } \\
\text { placebo: } \\
\text { 20/47 }(43 \%)\end{array}$ & $\begin{array}{l}\text { Inebilizumab: } \\
21 / 174 \\
(12 \%) ; \\
\text { placebo: } \\
22 / 56(39 \%)\end{array}$ & $\begin{array}{l}\text { Tocilizumab: } 8 / 59 \\
(14 \%) ; \\
\text { azathioprine: } \\
\text { 28/59 (47\%) }\end{array}$ & $\begin{array}{l}\text { Satralizumab: } \\
\text { 8/41 (20\%); } \\
\text { placebo: } \\
\text { 18/42 } \\
(43 \%)\end{array}$ & $\begin{array}{l}\text { Satralizumab: } \\
\text { 19/63 } \\
(30 \%) ; \\
\text { placebo: } \\
16 / 32 \\
(50 \%)\end{array}$ \\
\hline $\begin{array}{l}\text { Relapse free at } \\
48 \text { weeks }\end{array}$ & $\begin{array}{l}\text { Eculizumab: } \\
\text { 89.3\%; } \\
\text { placebo: } \\
50.6 \%\end{array}$ & N/A & $\mathrm{N} / \mathrm{A}$ & $\begin{array}{l}\text { Satralizumab: } \\
\text { 89\%; } \\
\text { placebo: } \\
66 \%\end{array}$ & $\begin{array}{l}\text { Satralizumab: } \\
\text { 76\%; } \\
\text { placebo: } \\
62 \%\end{array}$ \\
\hline $\begin{array}{l}\text { Relapse free at } \\
96 \text { weeks }\end{array}$ & $\begin{array}{l}\text { Eculizumab: } \\
\begin{array}{l}\text { 84.6\%; } \\
\text { placebo: } \\
\text { 35.8\% }\end{array}\end{array}$ & N/A & $\mathrm{N} / \mathrm{A}$ & $\begin{array}{l}\text { Satralizumab: } \\
\text { 78\%; } \\
\text { placebo: } \\
59 \%\end{array}$ & $\begin{array}{l}\text { Satralizumab: } \\
\text { 72\%; } \\
\text { placebo: } \\
51 \%\end{array}$ \\
\hline
\end{tabular}


decreased relapse rate and improved expanded disability status scale (EDSS) in patients with NMOSD [34]. Multiple studies since have re-demonstrated the efficacy and tolerability of rituximab [34-43].

A meta-analysis evaluating 25 independent studies showed that treatment with rituximab decreased annual relapse rate (ARR) (mean - 0.79) and EDSS (mean - 0.64) among NMOSD patients with notable moderate to high heterogeneity $\left(I^{2}=53-62\right)$ likely due to variable sample sizes $(n=2-100)$ [44]. Notably, a prospective study by Kim et al. of 100 patients with NMOSD followed up to 7 years showed that $94 \%$ of patients experienced a significant reduction in ARR and $70 \%$ were relapse free while on rituximab [43]. In addition, $96 \%$ of patients showed stabilization or improved EDSS. A retrospective study by Mealy et al. of 90 NMOSD patients observed that rituximab and mycophenolate mofetil were superior to azathioprine in ARR reduction (97.9\% and $90.2 \%$ vs. $72.1 \%$, respectively) with lower failure rates [45].

Some variations in rituximab dosing for NMOSD treatment have been reported $[22,35,37,40,41,46]$. The most commonly used rituximab regimen is an induction dose of $1000 \mathrm{mg}$ administered once or repeated twice 2 weeks apart $[22,41,45]$. Alternatively, a dosing regimen based on body mass index (375 mg/m² per week for 4 weeks) has been utilized [35, 39, 40].

Maintenance rituximab therapy is crucial for sustained suppression of B cell response [47], but consensus on optimal dosing regimen is lacking. A fixed regimen of $1000 \mathrm{mg}$ rituximab every 6 months (based on the average kinetics of B cell repopulation) is most commonly used to treat NMOSD patients [46, 48, 49]. Alternatively, an individualized approach, based upon reemergence of CD19-positive (CD19+) lymphocytes (0.1-2\% CD19+ cells among total lymphocytes), has also been utilized $[22,36,41,45,46]$.

Kim et al. have investigated the CD27-positive (CD27+) memory B cell population as a potential biomarker for monitoring efficacy and guiding rituximab re-dosing $[35,39,43]$. In a retrospective study of 30 patients with NMOSD, maintenance rituximab therapy $\left(375 \mathrm{mg} / \mathrm{m}^{2}\right)$ was administered when CD27+ memory cells reached $0.05 \%$ in the first 2 years and afterwards $0.1 \%$ of peripheral blood mononuclear cells (PBMCs), resulting in a significant reduction in ARR (87\%), stable or improved EDSS (93\%), and relapse freedom (60\%) over a 5-year period [35]. Of the 11/30 patients who experienced clinical relapses, only one showed CD27+ memory B cells below the threshold level. In contrast, CD19 counts were less than $0.5 \%$ of PBMCs in more than $50 \%$ of patients experiencing relapses. It was also demonstrated that maximal therapeutic efficacy of rituximab is achieved at a median of 8 infusions at $375 \mathrm{mg} / \mathrm{m}^{2}$ over 5 years [35].

Similarly, in a prospective study of 40 patients with NMOSD, Cohen et al. evaluated administering $1000 \mathrm{mg}$ of rituximab every 6 months compared to monitoring CD27 cell counts every 2-3 months and re-infusing rituximab at a dose of $1000 \mathrm{mg}$ when CD27 cell count surpassed 0.05\% of PBMCs [37]. All 6 relapses were in the setting of a CD27 count above the threshold, while 4 of the 6 relapses occurred with CD19 count below $0.5 \%$ of PBMCs.

Further validation of these cellular markers is needed to enable optimal dosing of rituximab because prolonged use predisposes to recurrent sino-pulmonary and urinary tract infections ( [50], Wingerchuk, AAN 2019). A study of 50 NMOSD patients treated with rituximab showed that 64\% (32/50) developed hypogammaglobulinemia and 10\% (5/10) developed severe infections [51]. 
In cases of severe hypogammaglobulinemia $(<150 \mathrm{mg} / \mathrm{dl})$ and/or frequent or severe infections accompanying immunoglobulin levels between 150 and $500 \mathrm{mg} / \mathrm{dl}$, supplementation of intravenous immunoglobulin (IVIG) $400 \mathrm{mg} / \mathrm{kg}$ every 4 weeks targeting a serum level $>800-1000$ is recommended (Wingerchuk, AAN 2019). Inadequate response to vaccines may also inform the decision to supplement immunoglobulins (Wingerchuk, AAN 2019) [52].

Rituximab is contraindicated in patients with active hepatitis B [53, 54]. There have been rare cases of PML following rituximab therapy, but none has been reported in NMOSD [55-57]. In addition, there is a FDA black box warning of severe infusion reactions, mucocutaneous reactions, and tumor lysis syndrome $[57,58]$.

The majority of patients with NMOSD, especially AQP4 seropositive patients, are highly responsive to long-term rituximab therapy; however, 15-45\% of patients continue to have relapses [35, 37, 40-43, 45]. A subset of patients, including those with larger body surface area, may show early repopulation of $B$ cells, mandating more frequent rituximab dosing based on monitoring B cell populations from peripheral blood samples [49]. In addition, neutralizing antibodies against rituximab, polymorphisms in the FCGR3A-F allele (which determines affinity of effector cell receptors towards IgG binding), and CNS compartmentalization of pathogenic B cells may also interfere with effective B cell depletion by rituximab [43], [59-61].

Azathioprine is a prodrug converted to 6-thioguanine nucleotides, which impairs DNA replication, resulting in apoptosis of $\mathrm{T}$ and B lymphocytes (Fig. 1; Table 1) [62]. Two retrospective studies demonstrated that treatment with azathioprine and concomitant prednisone decreased ARR by $76 \%$ and $70 \%$, respectively, among NMOSD patients [63, 64]. Costanzi et al. observed a greater reduction in ARR at doses of $2 \mathrm{mg} / \mathrm{kg} /$ day or higher; however, only $37 \%$ of NMOSD patients on azathioprine remained relapse free after 24 months [63]. In addition, 38/99 patients discontinued azathioprine due to side effects, including a significant risk of cancer [63].

Azathioprine is administered at a target dose of $2.5-3.0 \mathrm{mg} / \mathrm{kg} / \mathrm{day}$ with monthly monitoring of complete blood counts and a goal rise in mean corpuscular volume (MCV) of at least 5 points compared to baseline as an indicator of optimal dosing [63]. It takes several months for azathioprine to exhibit its full effect, so concomitant high-dose steroid treatment is recommended for the first 6 months, followed by a slow taper over 3-6 months [63]. Long-term concomitant steroid therapy at low doses may be required to maintain remission in some patients.

Mycophenolate mofetil is a prodrug of mycophenolic acid and a reversible inhibitor of inosine monophosphate dehydrogenase, which is involved in guanosine nucleotide synthesis, essential for $\mathrm{T}$ and $\mathrm{B}$ cell proliferation (Fig. 1; Table 1) [65]. In a retrospective study of 24 NMOSD patients, Jacob et al. observed that a median daily dose of $2000 \mathrm{mg}$ (750-3000 mg per day) significantly reduced the median annualized relapse rate (1.3-0.09) and stabilized or improved EDSS in $91 \%$ of patients [66]. Similarly, Huh et al. showed 
reduction of ARR (88\%), EDSS score stabilization or improvement (91\%), and remission $(60 \%)$ in a study of 59 NMOSD patients [67]. Discontinuation rates were $21 \%$ and $24 \%$, respectively $[66,67]$. Mycophenolate mofetil has an FDA black box warning for malignancy, especially lymphoproliferative and dermatological malignancies. It also predisposes to infections, including PML [55]. Concomitant administration of high-dose steroids is recommended when initiating mycophenolate mofetil due to delayed efficacy [68].

\section{New maintenance therapies}

\section{Eculizumab}

Eculizumab is a humanized monoclonal antibody that inhibits complement protein $\mathrm{C} 5$, preventing its cleavage into $\mathrm{C} 5 \mathrm{a}$ and $\mathrm{C} 5 \mathrm{~b}$, thereby interfering with formation of the membrane attack complex (Fig. 1; Table 1) [69]. The safety and efficacy of eculizumab were evaluated in the Prevention of Relapses in Neuromyelitis Optica (PREVENT) trial, a phase 3, randomized, double-blind, placebo-controlled, time-to-event study of AQP4 seropositive patients with NMOSD (Table 2) [70].

AQP4 seropositive NMOSD patients meeting the 2006 or 2007 diagnostic criteria, ages 18 years or older, with EDSS less than 7, who had experienced at least two relapses in the previous 12 months or three relapses in the previous 24 months with at least one relapse in the previous 12 months were included in the study. Those recently treated with rituximab, mitoxantrone, IVIG, and prednisone $>20 \mathrm{mg}$ per day, or suffering from active bacterial infections were excluded. Since blocking the complement system increases the risk of infection with encapsulated bacteria, patients were vaccinated with Neisseria meningitides prior to administration of eculizumab. Patients were allowed continuing their prior immunosuppressive therapies (e.g., azathioprine, mycophenolate mofetil) and added either eculizumab or placebo. Eculizumab was administered at $900 \mathrm{mg}$ IV weekly for 4 doses followed by $1200 \mathrm{mg}$ IV every 2 weeks.

The primary efficacy end point was time to onset of first relapse. Relapse occurred in 3\% (3/96) in the eculizumab group and 43\% (20/47) in the placebo group (hazard ratio 0.06). The subgroup analysis revealed that, of patients who received concomitant immunosuppressive therapies, relapse occurred in 4\% (3/75) in the eculizumab group and 38\% (13/34) in the placebo group. The rate of serious adverse events was 27/100 patient-years among patients treated with eculizumab, whereas the rate was significantly higher among the placebo group at 55/100 patient-years. The most common side effects were upper respiratory tract infections and headaches. No patients experienced meningococcal infection; however, one patient who received concomitant azathioprine died of pulmonary infection from Streptococcus and Peptostreptococcus species, not known to be associated with complement deficiency [70].

Inebilizumab is a humanized monoclonal antibody that binds to B cell surface antigen CD19 [71] and depletes a broader range of B lymphocyte subsets compared to anti-CD20 monoclonal antibodies (Fig. 1; Table 1) [8, 33]. The safety and efficacy of inebilizumab were evaluated in the N-MOmentum trial, a 
Table 2. NMOSD therapeutic drugs, targets, and mechanisms of action. Conventional therapies are shown in blue, new maintenance therapies in green, and emerging therapies in gray

\begin{tabular}{|c|c|c|}
\hline Target & Drug & Mechanism of action \\
\hline \multirow[t]{4}{*}{ Lymphocytes } & $\begin{array}{l}\text { Azathioprine } \\
\text { Mycophenolate mofetil }\end{array}$ & Cytotoxic/cytostatic \\
\hline & Methotrexate & \\
\hline & Mitoxantrone & \\
\hline & Cyclophosphamide & \\
\hline \multirow[t]{8}{*}{ B cell therapies } & $\begin{array}{l}\text { Rituximab } \\
\text { Ocrelizumab }\end{array}$ & Anti-CD20 \\
\hline & Ofatumumab & \\
\hline & Obinutuzumab & \\
\hline & Ublituximab & \\
\hline & Inebilizumab & Anti-CD19 \\
\hline & CAR-T & T cells directed against CD19/20 \\
\hline & Bortezomib & $26 \mathrm{~S}$ proteasome inhibitor \\
\hline & Belimumab & Anti-BLyS \\
\hline Complement cascade & Eculizumab & Inhibits cleavage of $\mathrm{C} 5$ by $\mathrm{C} 5$ convertase \\
\hline Humoral immune response & $\begin{array}{l}\text { Tocilizumab } \\
\text { Satralizumab }\end{array}$ & Anti-IL-6 \\
\hline \multirow[t]{3}{*}{ Antibodies } & $\begin{array}{l}\text { Aquaporumab } \\
\mathrm{AQ}^{\mathrm{mab}}\end{array}$ & Anti-AQP4 \\
\hline & Imlifidase & IgG degrading enzyme from S. pyogenes (IdeS) \\
\hline & $\begin{array}{l}\text { Rozanolixizumab } \\
\text { Efgartigimod }\end{array}$ & FcRn inhibitor \\
\hline Blood-brain barrier & Bevacizumab & Anti-VEGF \\
\hline \multirow[t]{4}{*}{ Granulocytes } & Sivelestat & Neutrophil elastase inhibitor \\
\hline & Cetirizine & $\mathrm{H} 1$ antagonist \\
\hline & $\begin{array}{l}\text { Mepolizumab } \\
\text { Reslizumab }\end{array}$ & Anti-IL-5 \\
\hline & Benralizumab & Anti-IL-5 receptor \\
\hline \multirow[t]{3}{*}{ Immune tolerance } & aHSCT & Eradication of autoreactive $B$ and $T$ cells \\
\hline & Self-antigen stimulation & Shift in immune balance towards regulatory cells \\
\hline & Inverse DNA vaccination & Reduction of autoreactive antibodies \\
\hline
\end{tabular}

phase 2/3, randomized, double-blind, placebo-controlled, time-to-event study of AQP4 seropositive and AQP4 seronegative patients with NMOSD (Table 2) [72]. The inebilizumab group included 174 patients (92\% AQP4 seropositive) and the placebo group included 56 patients (93\% AQP4 seropositive). Of the 17 AQP4 seronegative patients, 7 had antibodies against MOG. 
Inclusion criteria included age of at least 18 years, diagnosis of NMOSD by the 2006 criteria, history of at least one relapse requiring rescue therapy in the previous year or at least two relapses requiring rescue therapy in the previous two years, and EDSS score of 8 or less. Exclusion criteria included treatment with rituximab or other B cell-depleting agents within the previous 6 months; IVIG within the previous 1 month; natalizumab, cyclosporin, methotrexate, mitoxantrone, cyclophosphamide, tocilizumab, or eculizumab within the previous 3 months; or alemtuzumab, total lymphoid irradiation, bone marrow transplant, or T cell vaccination therapy previously.

Inebilizumab at $300 \mathrm{mg}$ IV or placebo was administered on days 1 and 15 . In addition, all participants were given prednisone $20 \mathrm{mg}$ daily or equivalent dose of other glucocorticoids between days 1 and 14 and then tapered to day 21 to minimize the risk of relapse at treatment initiation. Patients were not concomitantly treated with other immunosuppressive therapies.

The primary efficacy end point was time to onset of first relapse. The trial was stopped early due to clear demonstration of efficacy. Relapse occurred in 12\% $(21 / 174)$ in the inebilizumab group and in $39 \%(22 / 56)$ in the placebo group (hazard ratio 0.27). In the subgroup analysis of patients who were AQP4 seropositive, relapse occurred in $11 \%(18 / 161)$ in the inebilizumab group and in $42 \%(22 / 52)$ in the placebo group (hazard ratio 0.23$)$. In the inebilizumab group, CD20 B cell counts decreased to less than $10 \%$ of baseline and remained at this low level for the duration of the randomized controlled period. In addition, among AQP4 seropositive patients, fewer had a statistically significant worsening of EDSS score, and cumulative number of MRI lesions and number of NMOSD-related inpatient hospitalizations were lower in the inebilizumab group than in the placebo group compared to baseline.

Serious adverse events occurred in 5\% (8/174) in the inebilizumab group and $9 \%(5 / 56)$ in the placebo group. The overall infection rate was unchanged among patients who received inebilizumab; however, 2\% (3/174) of patients developed transient grade 3 neutropenia. There were no malignancies observed during the study. Infusion-related reaction rates were similar between the inebilizumab and placebo groups. There were two deaths during the open label period. One patient in the placebo group developed pneumonia and a NMOSD relapse. The second patient died from neurologic decline and new brain lesions on MRI. One of three PCR tests on CSF was positive for JC virus; it is unclear if the death was treatment-related since a definitive diagnosis was not fully determined.

Tocilizumab is a humanized monoclonal antibody that targets the interleukin- 6 receptor, blocking interleukin-6-mediated inflammatory cascades (Fig. 1; Table 1) $[73,74]$. Two small pilot studies showed its efficacy in treatmentresistant AQP4 seropositive NMOSD [75, 76].

The TANGO trial is the first head-to-head prospective, randomized comparison study between an established and new therapeutic in NMOSD (Table 2) [77]. This phase 2, open label, time-to-event study conducted in China compared the safety and efficacy of tocilizumab and azathioprine in NMOSD. The tocilizumab group included 59 patients (85\% AQP4 seropositive) and the azathioprine group included 59 patients (90\% AQP4 seropositive). 
Tocilizumab at $8 \mathrm{mg} / \mathrm{kg}$ IV was administered every 4 weeks; patients received concomitant immunosuppressants for the first 12 weeks of treatment. Azathioprine was initiated at an oral dose of $25 \mathrm{mg}$ daily and increased by $25 \mathrm{mg}$ per day to a target of $2-3 \mathrm{mg} / \mathrm{kg} /$ day; patients received concomitant immunosuppressants for the first 24 weeks of treatment.

The primary efficacy end point was time to onset of first relapse. Relapse occurred in $14 \%(8 / 59)$ in the tocilizumab group and $47 \%(28 / 59)$ in the azathioprine group (hazard ratio 0.24). In the subgroup analysis of patients with concomitant autoimmune diseases, 9\% (3/34) in the tocilizumab group and 35\% (13/37) in the azathioprine group relapsed. There were no differences in risk of relapse among patients without concomitant autoimmune diseases. In addition, only $8 \%$ (5/59) in the tocilizumab group compared to $25 \%(15 / 59)$ in the azathioprine group had disability progression at 12 weeks. Serious adverse events occurred more frequently in the azathioprine group than in the tocilizumab group. There was one death in each group, but neither death was treatment-related.

Satralizumab is a humanized monoclonal antibody that targets the interleukin6 receptor with a longer half-life than tocilizumab (Fig. 1) [78]. The safety and efficacy of satralizumab were evaluated in the SAkuraSky and SAkuraStar trials, phase 3, randomized, double-blind, placebo-controlled, time-to-event studies of AQP4 seropositive (70\%) and AQP4 seronegative patients (30\%) with NMOSD (Table 2) [79, 80]. In the SAkuraSky trial, patients on prior immunosuppressive therapies (e.g., glucocorticoids, azathioprine, mycophenolate mofetil) continued these treatments at stable doses. In contrast, in the SAkuraStar trial, satralizumab monotherapy was compared to placebo without the use of concomitant immunosuppressive therapies. Satralizumab at a dose of $120 \mathrm{mg}$ subcutaneously or placebo was administered at weeks 0,2 , and 4 , and then every 4 weeks.

Inclusion criteria for the SAkuraSky trial included adolescents (age of at least 12 years) and adults, diagnosis of NMOSD by the 2006 criteria, history of at least two relapses in the previous 2 years with at least one relapse in the previous 12 months, and EDSS score of 6.5 or less. By comparison, the SAkuraStar trial only included adults (age of at least 18 years), diagnosis of NMOSD by the 2006 criteria, history of at least one relapse in the previous year, and EDSS score of 6.5 or less. Exclusion criteria for the SAkuraSky and SAkuraStar trials included treatment with rituximab within the previous 6 months; eculizumab or multiple sclerosis disease-modifying therapies within the previous 6 months; antiCD4 agents, cladribine, or mitoxantrone within 2 years; or IL-6 targets, alemtuzumab, total-body irradiation, or bone marrow transplantation previously. The primary efficacy end point for both trials was time to onset of first relapse.

In the SAkuraSky trial, relapse occurred in $20 \%(8 / 41)$ in the satralizumab group and $43 \%$ (18/42) in the placebo group (hazard ratio 0.38). Further subgroup analysis revealed that $11 \%(3 / 27)$ of AQP4 seropositive NMOSD patients in the satralizumab group experienced relapses compared to $43 \%$ (12/ 28 ) in the placebo group (hazard ratio 0.21). In AQP4 seronegative cases, 
relapse occurred in 36\% (5/14) in the satralizumab group and 43\% (6/14) in the placebo group (hazard ratio 0.66).

In the SAkuraStar trial, relapse occurred in 30\% (19/63) in the satralizumab group and 50\% (16/32) in the placebo group (hazard ratio 0.45). Subgroup analysis showed that 22\% (9/41) of AQP4 seropositive NMOSD patients treated with satralizumab experienced relapses compared to $57 \%(13 / 23)$ in the placebo group (hazard ratio 0.26). In the AQP4 seronegative subgroup, relapse occurred in $46 \%(10 / 22)$ in the satralizumab group and 33\% (3/9) in the placebo group (hazard ratio 1.19).

Serious adverse events occurred in $17 \%$ of satralizumab-treated and $21 \%$ of placebo-treated NMOSD patients in the SAkuraSky trial. Similarly, 19\% of satralizumab-treated and $16 \%$ of placebo-treated NMOSD patients experienced adverse events in the SAkuraStar trial.

Comparable rates of infections were observed between the satralizumab and placebo groups. In the SAkuraSky trial, injection-related reactions were more frequent in the satralizumab (12\%) group than in the placebo (5\%) group. There were no deaths in either clinical trial.

\section{Therapeutic options in pregnancy}

NMOSD has a large female predominance, including women of childbearing age [81]. Disease activity can worsen during pregnancy and following delivery [81-83]. AQP4 and MOG antigens are present in the placenta, and women with NMOSD are at increased risk of pregnancy complications [82]. Elevated estrogen levels during pregnancy alter Th1, Th2, and Th17 cell ratios, creating a proinflammatory environment that impairs fetomaternal tolerance [81, 82].

Among the therapeutic options for NMOSD, methylprednisolone, rituximab, azathioprine, and IVIG may be relatively safe for use in pregnancy but are not without potential risks to the fetus. Glucocorticoids are associated with cleft palate formation and low birth weight, especially with exposure during early gestation [84]. Therefore, plasmapheresis may be preferred for a relapse during the first trimester. Rituximab has a mildly increased risk of miscarriage and premature birth $[85,86]$. B cell depletion occurs in neonates but is typically transient with resolution by 6 months of age [85]. Azathioprine has been associated with cardiac septal defects, premature birth, and low birth weight $[87,88]$. IVIG has also been associated with low birth weight [89].

For patients with very severe NMOSD, tocilizumab may be considered [82]. Tocilizumab has been associated with an increased risk of miscarriage and preterm birth [90]. It also has a slightly increased risk of fetal malformations compared to the risk in the general population [90].

Mycophenolate mofetil has a $45 \%$ probability of spontaneous abortion and $26 \%$ incidence of major fetal malformations and, therefore, is strongly contraindicated during pregnancy [91]. Women taking mycophenolate mofetil should be on effective contraception. Mycophenolate mofetil should be stopped at least 6 weeks before planned conception [82].

The pregnancy risks of eculizumab, inebilizumab, and satralizumab need to be investigated. Eculizumab has been safely used in pregnancy in women with paroxysmal nocturnal hemoglobinuria, atypical hemolytic uremic syndrome, and elevated liver enzymes and low platelet syndrome [92]. Like rituximab, 
inebilizumab is expected to cause transient B cell depletion in the newborn. Satralizumab may be associated with an increased risk of miscarriage and preterm birth, as has been the case for other anti-IL-6 therapies [90].

\section{MOG-associated disease}

Emerging evidence suggests that there are clinical and pathological features unique to MOG antibody-associated disease [6, 93, 94]. MOG antibodies are found in about $25 \%$ of seronegative NMOSD [4, 5]. However, the spectrum of clinical presentations goes beyond NMOSD. The most common presentation is optic neuritis, which is frequently bilateral $[93,94]$. In addition, MOGantibody associated disease can present with brainstem or encephalopathic syndromes such as acute disseminated encephalomyelitis [93, 94]. The clinical course of MOG-antibody associated disease can be monophasic, but relapsing disease has been reported in as many as $44-88 \%$ of patients [94-99]. Compared to patients with AQP4 seropositive NMOSD, MOG seropositive patients have a lower EDSS with lower risk of visual and motor disability [100].

MOG-antibody associated disease appears to target oligodendrocytes while preserving astrocytes and AQP4, as shown in histopathological analysis of CNS lesions from brain biopsy samples [6]. Plasmablasts generate MOG IgG antibodies, which bind to MOG on oligodendrocytes, leading to demyelination [82]. The majority of cases have IgG1 antibodies, but IgG2, IgG3, and IgG4 antibodies can also be present [101]. While our understanding of T cell function in MOG-associated disease is limited, it is hypothesized that T follicular helper cells may play a critical role in the inflammatory response by mediating B cell maturation [102].

The approach to treatment is extrapolated from the management of AQP4 seropositive NMOSD [103]. MOG-associated disease appears to be highly steroidresponsive and, in some cases, steroid-dependent [104]. As such, acute relapses are typically treated with high-dose IV methylprednisolone for 3-5 days (Fig. 2). Acute attacks that respond poorly to steroids can be treated with PLEX [96, 103].

The optimal disease-modifying strategy is not well established. The most frequently used approach has been an oral prednisone taper over 1 to 12 months following high-dose IV steroids [103] (Fig. 2). There is some evidence that persistent MOG antibody seropositivity may predict relapse [105]. Therefore, repeating MOG antibody testing after 3-12 months may be helpful to inform clinical decision-making regarding initiation of maintenance immunosuppressive therapy [106].

Rituximab, azathioprine, mycophenolate mofetil, and IVIG have been shown to decrease risk of relapse and improve disability outcomes [93, 96, 107]. In a retrospective study of 125 patients with MOGantibody associated disease, Cobo-Calvo et al. showed a reduction in mean annualized relapse rate from 1.08 to 0.43 with rituximab, 1.05 to 0.43 with azathioprine, and 1.20 to 0.23 with mycophenolate mofetil, with overall EDSS stabilization in all 3 subgroups [107]. In another retrospective multicenter study, Chen et al. found that $74 \%$ of patients had a relapse on mycophenolate mofetil, $61 \%$ of patients had a relapse on rituximab, and 59\% of patients had a relapse on azathioprine, whereas only $20 \%$ of patients had a relapse on IVIG, suggesting that 
maintenance IVIG therapy may be the most efficacious of these treatments [108].

\section{Emerging therapeutic strategies}

Immunotherapies used for the treatment of autoimmune and rheumatologic conditions as well as malignancies may have therapeutic potential in NMOSD (Table 1).

\section{Targeting B cells}

There are several anti-CD20 monoclonal antibodies, including ocrelizumab, ofatumumab, and obinutuzumab, that could be repurposed in NMOSD (Fig. 1). Ublituximab, in particular, was investigated in an open label, safety and proof of concept trial of $5 \mathrm{AQP} 4$ seropositive patients. Ublituximab was administered once within 5 days of high-dose corticosteroid treatment [109]. There were no severe adverse effects, and the EDSS score returned to baseline.

In addition, bortezomib, a $26 \mathrm{~S}$ proteasome inhibitor FDA-approved for hematological malignancies, has been shown to effectively decrease relapses, AQP4 antibody titers, and B cell counts (especially plasma cells) in highly active NMOSD (NCT02893111) [110]. Further potential B cell-mediated therapeutics for NMOSD include chimeric antigen receptor (CAR) T cell therapy and belimumab, an inhibitor of B lymphocyte stimulator (BLyS) [111].

\section{Targeting AQP4 antibodies}

Tradtrantip and colleagues showed that transforming pathogenic AQP4 antibodies into inactive antibodies by microbial-mediated deglycosylation of IgG heavy chain yielded positive results in animal models of NMOSD [112, 113]. This suggests that imlifidase, an IgG-degrading bacterial enzyme that cleaves IgG molecules into Fab and Fc segments, may be effective in AQP4 seropositive NMOSD [114]. Immunogenicity and safety are of concern with use in the human population. A similar therapeutic approach to downregulate pathogenic autoantibodies could be considered for rozanolixizumab and efgartigimod, inhibitors of neonatal Fc receptors (FcRn) crucial for antibody stability [115].

Aquaporumab is a recombinant monoclonal antibody derived from clonally expanded mouse CSF plasma cells with a point mutation in the area that codes for effector Fc IgG function, abolishing complement and cell-based cytotoxicity $[116,117]$. In a proof of concept study, aquaporumab prevented formation of new NMO lesions, likely through steric competition with pathologic AQP4 antibodies [117]. Furthermore, Duan et al. have described $A^{\mathrm{mab}}{ }^{\text {, }}$ which has an eightfold increased binding affinity to the AQP4 receptor compared to aquaporumab [118].

\section{Targeting the blood-brain barrier}

Shimizu et al. demonstrated that antibodies targeting brain microvascular endothelial cells (BMEC) were present in sera of 10/14 NMO patients, while being absent in MS and healthy controls [119]. There is evidence that vascular endothelial growth factor (VEGF)-neutralizing antibodies restore BBB integrity 
and anti-BMEC antibodies promote BBB disruption via VEGF, facilitating CNS entry of pathogenic AQP4 antibodies [119, 120]. In light of these findings, bevacizumab, a monoclonal immunoglobulin that targets VEGF, has been considered for use in treatment of NMOSD. An open label phase $1 \mathrm{~b}$ study showed a favorable safety profile and 3/6 patients recovered to their baseline EDSS [121].

\section{Targeting the complement cascade}

Blocking the $\mathrm{C} 1$ component of the complement cascade prevents formation of proinflammatory anaphylatoxins $\mathrm{C} 3 \mathrm{a}$ and $\mathrm{C} 3 \mathrm{~b}$ while preserving the lectin pathway, which is important for neutralizing encapsulated bacteria. $\mathrm{C}_{1} \mathrm{q}^{\mathrm{mab}}$, a monoclonal antibody against $\mathrm{C} 1 \mathrm{q}$ component, significantly reduced complement-dependent cytotoxicity in animal models [122]. Furthermore, Cinryze, a C1 esterase inhibitor, was shown to be safe as an add-on therapy to steroids for management of acute NMOSD relapses in an open label, phase 1b trial [123]. Nine of 10 patients returned to their baseline EDSS score.

\section{Targeting granulocytes}

Neutrophils and eosinophils are highly prevalent in NMOSD lesions [10, 124]. Animal models suggest that granulocytes mediate NMO pathogenesis. In particular, neutrophil entry into the CNS is an early step in the formation of NMO lesions [125] and blocking neutrophil elastase helps reduce neutrophil entrance into the brain [126]. As such, sivelestat, a neutrophil elastase inhibitor approved in Japan and Korea for ARDS treatment [127], is being tested in acute NMO relapses (UMIN000010094).

Cetirizine, a second-generation $\mathrm{H} 1$ antagonist, stabilizes eosinophil degranulation. A small open label add-on pilot study showed a decrease in ARR in cetirizine-treated NMO patients [128]. Anti-IL-5 agents, which deplete eosinophils, may also be considered for use in NMOSD [129].

\section{Restoring immune tolerance}

Autologous hematopoietic stem cell transplantation (HSCT) is used in treatment refractory and severe autoimmune conditions to reinstitute immune tolerance [130]. The two largest studies of HSCT in NMO included 13 and 16 patients, respectively [131, 132]. Greco et al. used heterogenous conditioning regimens, none of which incorporated rituximab. In contrast, Burt et al. utilized the same regimen for all patients, which included cyclophosphamide, rituximab, antithymocyte globulin, and plasmapheresis. In Greco et al.'s study, relapse-free survival was $10 \%$ and progression-free survival was $48 \%$, whereas in Burt et al.'s study, relapse-free survival was $80 \%$ and progression-free survival was $90 \%$. Nine of 11 AQP4 seropositive patients in Burt et al.'s study seroconverted to AQP4 seronegative upon HSCT and all of them remained relapse free at last follow-up despite the fact that two regained AQP4 seropositive status 2-4 years after HSCT. The two patients who remained AQP4 seropositive throughout the study were the ones who had clinical relapses. In Greco et al.'s study, 8/10 AQP4 seropositive patients remained seropositive throughout the study. There was one death in both studies. These studies demonstrate a potential immunoablative framework for applying HSCT in NMOSD. 
Tolerogenic DNA vaccination, autoreactive $T$ cell vaccination, and regulatory $\mathrm{T}$ cell-based therapies are other theoretical approaches for further investigation in NMOSD [133-135]. There has also been consideration of tolerizing against self-antigens. In a phase $1 \mathrm{~b}$ trial, AQP4 peptide loaded autologous tolerogenic dendritic cells were administered IV in 4 patients with NMO [136]. The procedure was well tolerated, and the patients remained in remission with stable EDSS. There was a significant increase in regulatory T cells and IL-10, an antiinflammatory cytokine, at 12-week follow-up.

\section{Conclusions}

NMOSD is a CNS demyelinating disorder characterized by severe clinical relapses that can cause permanent disability. Relapses are treated with highdose steroids and plasmapheresis. To prevent relapses and disease progression, patients are maintained on immunosuppressive therapies, most commonly rituximab, azathioprine, and mycophenolate mofetil.

In recent years, the treatment landscape for NMOSD has expanded, making therapeutic choices more complex. Landmark clinical trials have demonstrated that eculizumab, inebilizumab, and satralizumab are efficacious therapies with reasonable safety profiles for AQP4 seropositive NMOSD. In the N-MOmentum and SAkuraStar trials, respectively, inebilizumab and satralizumab were directly compared with placebo. Inebilizumab was also shown to decrease disability progression. Based on inclusion criteria for the N-MOmentum and SAkuraStar trials, inebilizumab and satralizumab may be beneficial in patients with newly diagnosed AQP4 seropositive NMOSD. AQP4 seronegative patients were included, but these trials were not sufficiently powered to assess the response in this subgroup, especially those with MOG-associated disease; thus, findings are primarily applicable to AQP4 seropositive patients. Moreover, limited data in these trials showed that these therapies might not have the same therapeutic benefits in AQP4 seronegative patients. Further studies are needed to evaluate treatment strategies for AQP4 seronegative NMOSD and MOG-associated disease. In the PREVENT trial, eculizumab was added to baseline immunosuppressive treatments in approximately $75 \%$ of patients with AQP4 seropositive NMOSD. Therefore, only approximately $25 \%$ of the patient cohort represented direct comparison to placebo. Notably, we do not yet have data comparing the efficacy of eculizumab, inebilizumab, and satralizumab to one another.

Prior to FDA approval of these three new medications, in our practice, we have used rituximab as a first-line therapy for NMOSD. Patients who have relapsed on rituximab have been transitioned to azathioprine or mycophenolate mofetil. In light of the N-MOmentum and SAkuraStar trials and recent regulatory approvals, we propose that inebilizumab and satralizumab may also be considered for use as first-line therapies for AQP4 seropositive NMOSD. Based on the PREVENT trial, eculizumab may be used as an add-on therapy for AQP4 seropositive patients who have relapses on azathioprine or mycophenolate mofetil. Inclusion criteria in this trial limit wider extrapolation of eculizumab's therapeutic effects when used as monotherapy or for newly 
diagnosed NMOSD, although it still might be reasonable to consider eculizumab in these settings as well.

Choice of therapy will be influenced by factors including frequency and route of administration (subcutaneous injection vs. intravenous infusion), side effect profile, and cost. Individual patient factors, such as age, co-morbidities, and pregnancy plans, may also weigh into the decision.

These new medications provide targeted and specific immunotherapy, allowing for treatment by way of a variety of pathophysiologic mechanisms of action. When switching between medications, some caution is advised since the use of a disease-modifying therapy within the previous 3-6 months was one of the most commonly used exclusion criteria in the trials.

We suspect that individualized approaches to re-dosing will be of interest in inebilizumab administration, as has been the case for rituximab monitoring with CD19 and particularly CD27 cell counts. Long-term safety will need to be closely monitored once these new medications become available.

In addition to the three new, recently FDA-approved medications, there are a multitude of promising treatment options on the horizon. The future is bright as therapeutic options increase, reshaping the lives of patients with NMOSD.

\section{References and Recommended Reading}

1. Wingerchuk DM, Banwell B, Bennett JL, Cabre P, Carroll W, Chitnis T, et al. International consensus diagnostic criteria for neuromyelitis optica spectrum disorders. Neurology. 2015;85(2):177-89.

2. Kim W, Park MS, Lee SH, Kim SH, Jung IJ, Takahashi T, et al. Characteristic brain magnetic resonance imaging abnormalities in central nervous system aquaporin-4 autoimmunity. Mult Scler. 2010 Oct;16(10):1229-36.

3. Han J, Yang M-G, Zhu J, Jin T. Complexity and wide range of neuromyelitis optica spectrum disorders: more than typical manifestations. Neuropsychiatr Dis Treat. 2017;13:2653-60.

4. Flanagan EP. Neuromyelitis optica spectrum disorder and other non-multiple sclerosis central nervous system inflammatory diseases. Continuum (Minneapolis, Minn). 2019, 25;(3):815-44

5. Wingerchuk DM. Immune-mediated myelopathies. CONTINUUM: Lifelong Learning in Neurology. 2018;24(2):497-522.

6. Weber MS, Derfuss T, Metz I, Brück W. Defining distinct features of anti-MOG antibody associated central nervous system demyelination. Ther Adv Neurol Disord. 2018;11:175628641876208.

7. Bennett JL, O'Connor KC, Bar-Or A, Zamvil SS, Hemmer B, Tedder TF, et al. B lymphocytes in neuromyelitis optica. Neurology(R) neuroimmunology \& neuroinflammation. 2015;2(3):e104.
8. LeBien TW, Tedder TF. B lymphocytes: how they develop and function. Blood. 2008;112(5):1570-80.

9. Chihara N, Aranami T, Sato W, Miyazaki Y, Miyake S, Okamoto $\mathrm{T}$, et al. Interleukin 6 signaling promotes anti-aquaporin 4 autoantibody production from plasmablasts in neuromyelitis optica. Proc Natl Acad Sci U S A. 2011;108(9):3701-6.

10. Lucchinetti CF, Guo Y, Popescu BF, Fujihara K, Itoyama $\mathrm{Y}$, Misu T. The pathology of an autoimmune astrocytopathy: lessons learned from neuromyelitis optica. Brain Pathol. 2014;24(1):83-97.

11. Soltys J, Liu Y, Ritchie A, Wemlinger S, Schaller K, Schumann H, et al. Membrane assembly of aquaporin4 autoantibodies regulates classical complement activation in neuromyelitis optica. J Clin Invest. 2019;129(5):2000-13.

12. Pohl M, Kawakami N, Kitic M, Bauer J, Martins R, Fischer $\mathrm{M}$, et al. T cell-activation in neuromyelitis optica lesions plays a role in their formation. Acta Neuropathol. Commun. 2013;1(1):85.

13. Pohl M, Fischer M, Mader S, Schanda K, Kitic M, Sharma R, et al. Pathogenic T cell responses against aquaporin 4. Acta Neuropathol. 2011;122(1):21-34.

14. Mitsdoerffer M, Kuchroo V, Korn T. Immunology of neuromyelitis optica: a T cell-B cell collaboration: immunology of neuromyelitis optica. Ann N Y Acad Sci. 2013;1283(1):57-66. 
15. Cruz-Herranz A, Sagan SA, Sobel RA, Green AJ, Zamvil SS. T cells targeting neuromyelitis optica autoantigen aquaporin-4 cause paralysis and visual system injury. J Nat Sci. 2017 May;3(5):e358.

16. Varrin-Doyer M, Spencer CM, Schulze-Topphoff U, Nelson PA, Stroud RM, Cree BA, et al. Aquaporin 4specific $T$ cells in neuromyelitis optica exhibit a Th17 bias and recognize Clostridium $\mathrm{ABC}$ transporter. Ann Neurol. 2012;72(1):53-64.

17. Kimura A, Kishimoto T. IL-6: regulator of Treg/Th17 balance. Eur J Immunol. 2010;40(7):1830-5.

18. Uzawa A, Mori M, Arai K, Sato Y, Hayakawa S, Masuda $S$, et al. Cytokine and chemokine profiles in neuromyelitis optica: significance of interleukin-6. Mult Scler. 2010;16(12):1443-52.

19. Zhang Y, Yao X, Gao M, Ding J, Hong R, Huang H, et al. Th2 axis-related cytokines in patients with neuromyelitis optica spectrum disorders. CNS neuroscience \& therapeutics. 2018;24(1):64-9.

20. Wingerchuk DM, Weinshenker BG. Neuromyelitis optica: clinical predictors of a relapsing course and survival. Neurology. 2003;60(5):848-53.

21. Cabre P, Gonzalez-Quevedo A, Bonnan M, Saiz A, Olindo S, Graus F, et al. Relapsing neuromyelitis optica: long term history and clinical predictors of death. J Neurol Neurosurg Psychiatry. 2009;80(10):1162-4.

22. Weinshenker BG, Wingerchuk DM. Neuromyelitis spectrum disorders. Mayo Clin Proc. 2017 Apr;92(4):663-79.

23. Kessler RA, Mealy MAR, Levy MM, PhD. Treatment of neuromyelitis optica Spectrum disorder: acute, preventive, and symptomatic. Curr Treat Options Neurol. 2016;18(1):1-15.

24. Sellner J, Boggild M, Clanet M, Hintzen RQ, Illes Z, Montalban X, et al. EFNS guidelines on diagnosis and management of neuromyelitis optica diagnosis and management of neuromyelitis optica. Eur J Neurol. 2010;17(8):1019-32.

25. Sherman EM, Han MHM. Acute and chronic management of neuromyelitis optica spectrum disorder. Curr Treat Options Neurol. 2015;17(11):1-14.

26. Kimbrough DJ, Fujihara K, Jacob A, Lana-Peixoto MA, Isabel Leite $\mathrm{M}$, Levy $\mathrm{M}$, et al. Treatment of neuromyelitis optica: review and recommendations. Multiple Sclerosis and Related Disorders. 2012;1(4):180-7.

27. Weinshenker BG, O'Brien PC, Petterson TM, Noseworthy JH, Lucchinetti CF, Dodick DW, et al. A randomized trial of plasma exchange in acute central nervous system inflammatory demyelinating disease. Ann Neurol. 1999;46(6):878-86.

28. Bonnan M, Valentino R, Debeugny S, Merle H, Fergé J, Mehdaoui $\mathrm{H}$, et al. Short delay to initiate plasma exchange is the strongest predictor of outcome in severe attacks of NMO spectrum disorders. J Neurol Neurosurg Psychiatry. 2018;89(4):346-51.

29. Kitley J, Elsone L, George J, Waters P, Woodhall M, Vincent A, et al. Methotrexate is an alternative to azathioprine in neuromyelitis optica spectrum disorders with aquaporin-4 antibodies. J Neurol Neurosurg Psychiatry. 2013;84(8):918-21.

30. Ramanathan RS, Malhotra K, Scott T. Treatment of neuromyelitis optica/neuromyelitis optica spectrum disorders with methotrexate. BMC Neurol. 2014;14:51.

31. Weinstock-Guttman B, Ramanathan M, Lincoff N, Napoli SQ, Sharma J, Feichter J, et al. Study of mitoxantrone for the treatment of recurrent neuromyelitis optica (Devic disease). Arch Neurol. 2006;63(7):957-63.

32. Yaguchi H, Sakushima K, Takahashi I, Nishimura H, Yashima-Yamada M, Nakamura M, et al. Efficacy of intravenous cyclophosphamide therapy for neuromyelitis optica spectrum disorder. Intern Med. 2013;52(9):969-72.

33. Greenfield AL, Hauser SL. B-cell therapy for multiple sclerosis: entering an era. Ann Neurol. 2018;83(1):1326.

34. Cree BA, Lamb S, Morgan K, Chen A, Waubant E, Genain C. An open label study of the effects of rituximab in neuromyelitis optica. Neurology. 2005;64(7):1270-2.

35. Kim SH, Huh SY, Lee SJ, Joung A, Kim HJ. A 5-year follow-up of rituximab treatment in patients with neuromyelitis optica spectrum disorder. JAMA neurology. 2013;70(9):1110-7.

36. Lu Q, Luo J, Hao H, Liu R, Jin H, Jin Y, et al. A long-term follow-up of rituximab treatment in 20 Chinese patients with neuromyelitis optica spectrum disorders. Mult. Scler. Relat. Disord. 2020;40:101933.

37. Cohen M, Romero G, Bas J, Ticchioni M, Rosenthal M, Lacroix R, et al. Monitoring CD27 + memory B-cells in neuromyelitis optica spectrum disorders patients treated with rituximab: results from a bicentric study. J Neurol Sci. 2017;373:335-8.

38. Lebrun C, Cohen M, Rosenthal-Allieri MA, Bresch S, Benzaken S, Marignier R, et al. Only follow-up of memory $\mathrm{B}$ cells helps monitor rituximab administration to patients with neuromyelitis optica spectrum disorders. Neurology and Therapy. 2018;7(2):373-83.

39. Kim SH, Kim W, Li XF, Jung IJ, Kim HJ. Repeated treatment with rituximab based on the assessment of peripheral circulating memory B cells in patients with relapsing neuromyelitis optica over 2 years. Arch Neurol. 2011;68(11):1412-20.

40. Annovazzi P, Capobianco M, Moiola L, Patti F, Frau J, Uccelli A, et al. Rituximab in the treatment of neuromyelitis optica: a multicentre Italian observational study. Eur J Neurol. 2016;263(9):1727-35.

41. Cabre P, On behalf of Francophone Society of Multiple Sclerosis and OFSEP investigators, Mejdoubi M, Jeannin S, Merle H, Plumelle Y, et al. Treatment of neuromyelitis optica with rituximab: a 2-year prospective multicenter study. J Neurol. 2018;265(4):917-25.

42. Jacob A, Weinshenker BG, Violich I, McLinskey N, Krupp L, Fox RJ, et al. Treatment of neuromyelitis optica with rituximab: retrospective analysis of 25 patients. Arch Neurol. 2008;65(11):1443-8. 
43. Kim SH, Jeong IH, Hyun JW, Joung A, Jo HJ, Hwang $\mathrm{SH}$, et al. Treatment outcomes with rituximab in 100 patients with neuromyelitis optica: influence of FCGR3A polymorphisms on the therapeutic response to rituximab. JAMA neurology. 2015;72(9):989-95.

44. Damato V, Evoli A, Iorio R. Efficacy and safety of rituximab therapy in neuromyelitis optica spectrum disorders: a systematic review and meta-analysis. JAMA neurology. 2016;73(11):1342-8.

45. Mealy MA, Wingerchuk DM, Palace J, Greenberg BM, Levy M. Comparison of relapse and treatment failure rates among patients with neuromyelitis optica: multicenter study of treatment efficacy. JAMA neurology. 2014;71(3):324-30.

46. Greenberg BM, Graves D, Remington G, Hardeman P, Mann M, Karandikar N, et al. Rituximab dosing and monitoring strategies in neuromyelitis optica patients: creating strategies for therapeutic success. Mult Scler. 2012;18(7):1022-6.

47. Pellkofer HL, Krumbholz M, Berthele A, Hemmer B, Gerdes LA, Havla J, et al. Long-term follow-up of patients with neuromyelitis optica after repeated therapy with rituximab. Neurology. 2011;76(15):1310-5.

48. Roll P, Palanichamy A, Kneitz C, Dorner T, Tony HP. Regeneration of B cell subsets after transient B cell depletion using anti-CD20 antibodies in rheumatoid arthritis. Arthritis Rheum. 2006;54(8):2377-86.

49. Ellwardt E, Ellwardt L, Bittner S, Zipp F. Monitoring Bcell repopulation after depletion therapy in neurologic patients. Neurology(R) neuroimmunology \& neuroinflammation. 2018;5(4):e463.

50. Makatsori M, Kiani-Alikhan S, Manson AL, Verma N, Leandro M, Gurugama NP, et al.

Hypogammaglobulinaemia after rituximab treatmentincidence and outcomes. QJM: monthly journal of the Association of Physicians. 2014;107(10):821-8.

51. Tallantyre EC, Whittam DH, Jolles S, Paling D, Constantinesecu C, Robertson NP, et al. Secondary antibody deficiency: a complication of anti-CD20 therapy for neuroinflammation. J Neurol.

2018;265(5):1115-22.

52. Marcinnò A, Marnetto F, Valentino P, Martire S, Balbo A, Drago A, et al. Rituximab-induced hypogammaglobulinemia in patients with neuromyelitis optica spectrum disorders. Neurol

Neuroimmunol Neuroinflamm. 2018;5(6):e498.

53. Randall KL. Rituximab in autoimmune diseases. Aust Prescr. 2016;39(4):131-4.

54. Hoofnagle JH. Reactivation of hepatitis B. Hepatology. 2009;49(5 Suppl):156-65.

55. Chahin S, Berger J. A risk classification for immunosuppressive treatment-associated progressive multifocal leukoencephalopathy. J Neuro-Oncol.

2015;21(6):623-31.

56. Clifford DB, Ances B, Costello C, Rosen-Schmidt S, Andersson M, Parks D, et al. Rituximab-associated progressive multifocal leukoencephalopathy in rheumatoid arthritis. Arch Neurol. 2011;68(9):1156-64.
57. Ghrenassia E, Mariotte E, Azoulay E. Rituximab-related severe toxicity. Int J Crit Care Emerg Med. 2018;2018:579-96.

58. Salmon JH, Perotin JM, Morel J, Dramé M, Cantagrel A, Ziegler LE, et al. Serious infusion-related reaction after rituximab, abatacept and tocilizumab in rheumatoid arthritis: prospective registry data. Rheumatology (Oxford). 2018;57(1):134-9.

59. Li T, Zhang LJ, Zhang QX, Yang CS, Zhang C, Li YJ, et al. Anti-rituximab antibody in patients with NMOSDs treated with low dose rituximab. J Neuroimmunol. 2018;316:107-11.

60. Dunn N, Juto A, Ryner M, Manouchehrinia A, Piccoli L, Fink K, et al. Rituximab in multiple sclerosis: frequency and clinical relevance of anti-drug antibodies. Mult Scler. 2018;24(9):1224-33.

61. Sonia Boyer-Suavet, Marine Andreani, Maël Lateb, Benjamin Savenkoff, Vesna Brglez, Sylvia Benzaken, et al. Neutralizing anti-rituximab antibodies and relapse in membranous nephropathy treated with rituximab. Frontiers in Immunology 2020.

62. Ford LT, Berg JD. Thiopurine S-methyltransferase (TPMT) assessment prior to starting thiopurine drug treatment; a pharmacogenomic test whose time has come. J Clin Pathol. 2010;63(4):288-95.

63. Costanzi C, Matiello M, Lucchinetti CF, Weinshenker BG, Pittock SJ, Mandrekar J, et al. Azathioprine: tolerability, efficacy, and predictors of benefit in neuromyelitis optica. Neurology. 2011;77(7):659-66.

64. Bichuetti DB, Lobato de Oliveira EM, Oliveira DM, Amorin de Souza N, Gabbai AA. Neuromyelitis optica treatment: analysis of 36 patients. Arch Neurol. 2010;67(9):1131-6.

65. Allison AC, Eugui EM. The design and development of an immunosuppressive drug, mycophenolate mofetil. Springer Semin Immunopathol. 1993;14(4):353-80.

66. Jacob A, Matiello M, Weinshenker BG, Wingerchuk DM, Lucchinetti C, Shuster E, et al. Treatment of neuromyelitis optica with mycophenolate mofetil: retrospective analysis of 24 patients. Arch Neurol. 2009;66(9):1128-33.

67. Huh SY, Kim SH, Hyun JW, Joung AR, Park MS, Kim BJ, et al. Mycophenolate mofetil in the treatment of neuromyelitis optica spectrum disorder. JAMA neurology. 2014;71(11):1372-8.

68. Weinshenker BG, Wingerchuk DM. Neuromyelitis spectrum disorders. Mayo Clin Proc. 2017;92(4):66379.

69. Thomas TC, Rollins SA, Rother RP, Giannoni MA, Hartman SL, Elliott EA, et al. Inhibition of complement activity by humanized anti-C5 antibody and singlechain Fv. Mol Immunol. 1996;33(17-18):1389-401.

70. Pittock SJ, Berthele A, Fujihara K, Nakashima I, Kim HJ, Levy $M$, et al. Eculizumab in aquaporin-4-positive neuromyelitis optica spectrum disorder. N Engl J Med. 2019;381(7):614-25.

71. Chen D, Gallagher S, Monson NL, Herbst R, Wang Y. Inebilizumab, a B cell-depleting anti-CD19 antibody for the treatment of autoimmune neurological 
diseases: insights from preclinical studies. Journal of clinical medicine 2016;5(12).

72. Cree BAC, Bennett JL, Kim HJ, Weinshenker BG, Pittock SJ, Wingerchuk DM, et al. Inebilizumab for the treatment of neuromyelitis optica spectrum disorder (NMOmentum): a double-blind, randomised placebocontrolled phase 2/3 trial. Lancet (London, England). 2019;394(10206):1352-63.

73. Tanaka T, Narazaki M, Kishimoto T. Therapeutic targeting of the interleukin- 6 receptor. Annu Rev Pharmacol Toxicol. 2012;52(1):199-219.

74. Garbers C, Heink S, Korn T, Rose-John S. Interleukin-6: designing specific therapeutics for a complex cytokine. Nature reviews. Drug Des Discov. 2018;17(6):395412.

75. Ayzenberg I, Kleiter I, Schröder A, Hellwig K, Chan A, Yamamura T, et al. Interleukin 6 receptor blockade in patients with neuromyelitis optica nonresponsive to anti-CD20 therapy. JAMA neurology. 2013;70(3):3947.

76. Ringelstein M, Ayzenberg I, Harmel J, Lauenstein AS, Lensch E, Stögbauer F, et al. Long-term therapy with interleukin 6 receptor blockade in highly active neuromyelitis optica spectrum disorder. JAMA neurology. 2015;72(7):756-63.

77. Zhang C, Zhang M, Qiu W, Ma H, Zhang X, Zhu Z, et al. Safety and efficacy of tocilizumab versus azathioprine in highly relapsing neuromyelitis optica spectrum disorder (TANGO): an open-label, multicentre, randomised, phase 2 trial. The Lancet Neurology. 2020;19(5):391-401.

78. Igawa T, Ishii S, Tachibana T, Maeda A, Higuchi Y, Shimaoka $\mathrm{S}$, et al. Antibody recycling by engineered $\mathrm{pH}$-dependent antigen binding improves the duration of antigen neutralization. Nat Biotechnol. 2010;28(11):1203-7.

79. Yamamura T, Kleiter I, Fujihara K, Palace J, Greenberg B, Zakrzewska-Pniewska B, et al. Trial of satralizumab in neuromyelitis optica spectrum disorder. N Engl J Med. 2019;381(22):2114-24.

80. Traboulsee AP, Greenberg BMP, Bennett JLP, Szczechowski LM, Fox EP, Shkrobot SM, et al. Safety and efficacy of satralizumab monotherapy in neuromyelitis optica spectrum disorder: a randomised, double-blind, multicentre, placebo-controlled phase 3 trial. Lancet Neurol. 2020;19(5):402-12.

81. Davoudi V, Keyhanian K, Bove RM, Chitnis T. Immunology of neuromyelitis optica during pregnancy. Neurology: neuroimmunology \& neuroinflammation. Neurol Neuroimmunol Neuroinflamm. 2016;3(6):e288.

82. Mao-Draayer Y, Thiel S, Mills EA, Chitnis T, Fabian M, Katz Sand I, et al. Neuromyelitis optica spectrum disorders and pregnancy: therapeutic considerations. Nature reviews. Neurology. Nat Rev Neurol. 2020;16(3):154-70.

83. Klawiter EC, Bove R, Elsone L, Alvarez E, Borisow N, Cortez $\mathrm{M}$, et al. High risk of postpartum relapses in neuromyelitis optica spectrum disorder. Neurology. 2017;89(22):2238-44.

84. Park-Wyllie L, Mazzotta P, Pastuszak A, Moretti ME, Beique L, Hunnisett L, et al. Birth defects after maternal exposure to corticosteroids: prospective cohort study and meta-analysis of epidemiological studies. Teratology. 2000;62(6):385-92.

85. Das G, Damotte V, Gelfand JM, Bevan C, Cree BAC, Do $\mathrm{L}$, et al. Rituximab before and during pregnancy: a systematic review, and a case series in MS and NMOSD. Neurology: neuroimmunology \& neuroinflammation. Neurol Neuroimmunol Neuroinflamm. 2018;5(3):e453.

86. Chakravarty EF, Murray ER, Kelman A, Farmer P. Pregnancy outcomes after maternal exposure to rituximab. Blood. 2011;117(5):1499-506.

87. Cleary BJ, Källén B. Early pregnancy azathioprine use and pregnancy outcomes. Birth defects research. A clinical and molecular teratology. Birth Defects Res A Clin Mol Teratol. 2009;85(7):647-54.

88. Goldstein LH, Dolinsky G, Greenberg R, Schaefer C, Cohen-Kerem R, Diav-Citrin O, et al. Pregnancy outcome of women exposed to azathioprine during pregnancy. Birth defects research. A clinical and molecular teratology. Birth Defects Res A Clin Mol Teratol. 2007;79(10):696-701.

89. Huang Y, Wang Y, Zhou Y, Huang Q, Sun X, Chen C, et al. Pregnancy in neuromyelitis optica spectrum disorder: a multicenter study from South China. J Neurol Sci. 2017;372:152-6.

90. Hoeltzenbein M, Beck E, Rajwanshi R, Gøtestam Skorpen C, Berber E, Schaefer C, et al. Tocilizumab use in pregnancy: analysis of a global safety database including data from clinical trials and post-marketing data. Semin Arthritis Rheum. 2016;46(2):238-45.

91. Hoeltzenbein M, Elefant E, Vial T, Finkel-Pekarsky V, Stephens S, Clementi M, et al. Teratogenicity of mycophenolate confirmed in a prospective study of the European Network of Teratology Information Services. American journal of medical genetics. Part A. Am J Med Genet A. 2012;158A(3):588-96.

92. Sarno L, Tufano A, Maruotti GM, Martinelli P, Balletta MM, Russo D. Eculizumab in pregnancy: a narrative overview. J Nephrol. 2018;32(1):17-25.

93. Ramanathan S, Mohammad S, Tantsis E, Nguyen TK, Merheb V, Fung VSC, et al. Clinical course, therapeutic responses and outcomes in relapsing MOG antibodyassociated demyelination. J Neurol Neurosurg Psychiatry. 2018;89(2):127-37.

94. Cobo-Calvo A, Ruiz A, Maillart E, Audoin B, Zephir H, Bourre $\mathrm{B}$, et al. Clinical spectrum and prognostic value of CNS MOG autoimmunity in adults: the MOGADOR study. Neurology. 2018;90(21):e1858-69.

95. Dubey D, Pittock SJ, Krecke KN, Morris PP, Sechi E, Zalewski NL, et al. Clinical, radiologic, and prognostic features of myelitis associated with myelin oligodendrocyte glycoprotein autoantibody. JAMA neurology. 2019;76(3):301-9. 
96. Jarius S, Ruprecht K, Kleiter I, Borisow N, Asgari N, Pitarokoili $\mathrm{K}$, et al. MOG-IgG in NMO and related disorders: a multicenter study of 50 patients. Part 2: Epidemiology, clinical presentation, radiological and laboratory features, treatment responses, and longterm outcome. J Neuroinflammation. 2016;13:280.

97. Chen JJ, Flanagan EP, Jitprapaikulsan J, LópezChiriboga ASS, Fryer JP, Leavitt JA, et al. Myelin oligodendrocyte glycoprotein antibody-positive optic neuritis: clinical characteristics, radiologic clues, and outcome. Am J Ophthalmol. 2018;195:8-15.

98. Clinical presentation and prognosis in MOG-antibody disease: a UK study. Brain 2018;140(12):3128-3138.

99. Mariotto S, Ferrari S, Monaco S, Benedetti MD, Schanda K, Alberti D, et al. Clinical spectrum and IgG subclass analysis of anti-myelin oligodendrocyte glycoprotein antibody-associated syndromes: a multicenter study. J Neurol. 2017;264(12):2420-30.

100. Chang VTW. Chang H-. review: recent advances in the understanding of the pathophysiology of neuromyelitis optica spectrum disorder. Neuropathol Appl Neurobiol. 2019;46(3):199-218.

101. Mariotto S, Ferrari S, Monaco S, Benedetti MD, Schanda K, Alberti D, et al. Clinical spectrum and IgG subclass analysis of anti-myelin oligodendrocyte glycoprotein antibody-associated syndromes: a multicenter study. J Neurol. 2017;264(12):2420-30.

102. Li X, Wang L, Zhou L, ZhangBao J, Miao MZ, Lu C, et al. The imbalance between regulatory and memory B cells accompanied by an increased number of circulating T-follicular helper cells in MOG-antibodyassociated demyelination. Mult Scler Relat Disord. 2019;36:-101397.

103. Wynford-Thomas R, Jacob A, Tomassini V. Neurological update: MOG antibody disease. J Neurol. 2019;266(5):1280-6.

104. Chalmoukou K, Alexopoulos H, Akrivou S, Stathopoulos P, Reindl M, Dalakas MC. Anti-MOG antibodies are frequently associated with steroidsensitive recurrent optic neuritis. Neurol Neuroimmunol Neuroinflamm. 2015;2(4):e131.

105. Hyun J-W, Kim S-H, Jeong IH, Kong B, Kim G, Kim Y, et al. Longitudinal analysis of myelin oligodendrocyte glycoprotein antibodies in CNS inflammatory diseases. J Neurol Neurosurg Psychiatry. 2017;88(10):811-7.

106. Jarius S, Paul F, Aktas O, Asgari N, Dale RC, de Seze J, et al. MOG encephalomyelitis: international recommendations on diagnosis and antibody testing. J Neuroinflammation. 2018;15(1):1-10.

107. Cobo-Calvo A, Sepúlveda M, Rollot F, Armangué T, Ruiz A, Maillart E, et al. Evaluation of treatment response in adults with relapsing MOG-Ab-associated disease. J Neuroinflammation. 2019;16(1):1-12.

108. Chen JJ, Flanagan EP, Bhatti MT, Jitprapaikulsan J, Dubey D, Lopez Chiriboga AS, et al. Steroid-sparing maintenance immunotherapy for MOG-IgG associated disorder. Neurology. 2020;95(2):e111-20.
109. Mealy MA, Levy M. A pilot safety study of ublituximab, a monoclonal antibody against CD20, in acute relapses of neuromyelitis optica spectrum disorder. Medicine. 2019;98(25):e15944.

110. Zhang C, Tian DC, Yang CS, Han B, Wang J, Yang L, et al. Safety and efficacy of bortezomib in patients with highly relapsing neuromyelitis optica spectrum disorder. JAMA neurology. 2017;74(8):1010-2.

111. Tradtrantip L, Asavapanumas N, Verkman AS. Emerging therapeutic targets for neuromyelitis optica spectrum disorder. Expert Opin Ther Targets. 2020;24(3):219-29.

112. Tradtrantip L, Ratelade J, Zhang H, Verkman AS. Enzymatic deglycosylation converts pathogenic neuromyelitis optica anti-aquaporin-4 immunoglobulin G into therapeutic antibody. Ann Neurol. 2013;73(1):77-85.

113. Tradtrantip L, Asavapanumas N, Verkman AS. Therapeutic cleavage of anti-aquaporin- 4 autoantibody in neuromyelitis optica by an IgG-selective proteinase. Mol Pharmacol. 2013;83(6):1268-75.

114. Lonze BE, Tatapudi VS, Weldon EP, Min ES, Ali NM, Deterville CL, et al. IdeS (Imlifidase): a novel agent that cleaves human IgG and permits successful kidney transplantation across high-strength donor-specific antibody. Ann Surg. 2018;268(3):488-96.

115. Howard JF Jr, Bril V, Burns TM, Mantegazza R, Bilinska M, Szczudlik A, et al. Randomized phase 2 study of FcRn antagonist efgartigimod in generalized myasthenia gravis. Neurology. 2019;92(23):e266173.

116. Verkman AS, Phuan P, Asavapanumas N, Tradtrantip L. Biology of AQP4 and anti-AQP4 antibody: therapeutic implications for NMO. Brain Pathol. 2013;23(6):684-95.

117. Tradtrantip L, Zhang H, Saadoun S, Phuan PW, Lam C, Papadopoulos MC, et al. Anti-Aquaporin-4 monoclonal antibody blocker therapy for neuromyelitis optica. Ann Neurol. 2012;71(3):314-22.

118. Duan T, Tradtrantip L, Phuan P, Bennett JL, Verkman AS. Affinity-matured 'aquaporumab' anti-aquaporin4 antibody for therapy of seropositive neuromyelitis optica spectrum disorders. Neuropharmacology. 2020;162:107827.

119. Shimizu F, Sano Y, Takahashi T, Haruki H, Saito K, Koga $M$, et al. Sera from neuromyelitis optica patients disrupt the blood-brain barrier. J Neurol Neurosurg Psychiatry. 2012;83(3):288-97.

120. Shimizu F, Schaller KL, Owens GP, Cotleur AC, Kellner D, Takeshita Y, et al. Glucose-regulated protein 78 autoantibody associates with blood-brain barrier disruption in neuromyelitis optica. Sci Transl Med. 2017:9(397).

121. Mealy MA, Shin K, John G, Levy M. Bevacizumab is safe in acute relapses of neuromyelitis optica. Clin. Exp. Immunol. 2015;6(4):413-8.

122. Phuan $\mathrm{P}$, Zhang $\mathrm{H}$, Asavapanumas N, Leviten $\mathrm{M}$, Rosenthal A, Tradtrantip L, et al. C1q-targeted monoclonal antibody prevents complement- 
dependent cytotoxicity and neuropathology in in vitro and mouse models of neuromyelitis optica. Acta Neuropathol. 2013;125(6):829-40.

123. Levy M, Mealy MA. Purified human C1-esterase inhibitor is safe in acute relapses of neuromyelitis optica, Neurology(R) neuroimmunology \& neuroinflammation. 2014;1(1):e5.

124. Jarius S, Paul F, Franciotta D, Ruprecht K, Ringelstein $\mathrm{M}$, Bergamaschi $\mathrm{R}$, et al. Cerebrospinal fluid findings in aquaporin- 4 antibody positive neuromyelitis optica: results from 211 lumbar punctures. J Neurol Sci. 2011;306(1-2):82-90.

125. Saadoun S, Waters P, MacDonald C, Bell BA, Vincent A, Verkman AS, et al. Neutrophil protease inhibition reduces neuromyelitis optica-immunoglobulin G-induced damage in mouse brain. Ann Neurol. 2012;71(3):323-33.

126. Herges K, de Jong BA, Kolkowitz I, Dunn C, Mandelbaum G, Ko RM, et al. Protective effect of an elastase inhibitor in a neuromyelitis optica-like disease driven by a peptide of myelin oligodendroglial glycoprotein. Mult Scler. 2012;18(4):398-408.

127. Kawasaki Y, Aikawa N. Clinical utility of the neutrophil elastase inhibitor sivelestat for the treatment of acute respiratory distress syndrome. Ther Clin Risk Manag. 2014;621.

128. Zhang H, Verkman AS. Eosinophil pathogenicity mechanisms and therapeutics in neuromyelitis optica. J Clin Invest. 2013;123(5):2306-16.

129. Roufosse F. Targeting the interleukin-5 pathway for treatment of eosinophilic conditions other than asthma. Front med. 2018;5:49.

130. Malmegrim KCR, Lima-Júnior JR, Arruda LCM, de Azevedo JTC, de Oliveira GLV, Oliveira MC. Autologous hematopoietic stem cell transplantation for autoimmune diseases: from mechanistic insights to biomarkers. Front Immunol. 2018;9:2602.
131. Burt RK, Han X, Burns C, Balabanov R, Gastala J, Jovanovic B, et al. Autologous nonmyeloablative hematopoietic stem cell transplantation for neuromyelitis optica. Neurology. 2019;93(18):E1732-41.

132. Greco R, Bondanza A, Oliveira MC, Badoglio M, Burman J, Piehl F, et al. Autologous hematopoietic stem cell transplantation in neuromyelitis optica: a registry study of the EBMT Autoimmune Diseases Working Party. Mult Scler J. 2015;21(2):189-97.

133. Garren H, Robinson WH, Krasulová E, Havrdová E, Nadj C, Selmaj K, et al. Phase 2 trial of a DNA vaccine encoding myelin basic protein for multiple sclerosis. Ann Neurol. 2008;63(5):611-20.

134. Steinman L, Bar-Or A, Behne JM, Benitez-Ribas D, Chin PS, Clare-Salzler M, et al. Restoring immune tolerance in neuromyelitis optica: Part I. Neurol Neuroimmunol Neuroinflamm. 2016;3(5):e276.

135. Bar-Or A, Steinman L, Behne JM, Benitez-Ribas D, Chin PS, Clare-Salzler M, et al. Restoring immune tolerance in neuromyelitis optica: Part II. Neurol Neuroimmunol Neuroinflamm, 2016. 3(5):e277.

136. Zubizarreta I, Flórez-Grau G, Vila G, Cabezón R, España C, Andorra M, et al. Immune tolerance in multiple sclerosis and neuromyelitis optica with peptide-loaded tolerogenic dendritic cells in a phase 1 b trial. Proc Natl Acad Sci U S A. 2019;116(17):8463-70.

\section{Publisher's Note}

Springer Nature remains neutral with regard to jurisdictional claims in published maps and institutional affiliations. 